\title{
The effects of cue-reversal as a function of amount of prior learning on a shock-motivated discrimination'
}

\author{
Charles L. Sheridan 2 and Charles N. Bennett \\ UNIVERSITY OF MISSOURI AND VA HOSPITAL, KANSAS CITY
}

\begin{abstract}
Abstraet
The effect of cue-reversal as a function of amount of prior learning on a shock-motivated black-white discrimination was measured in 35 albino rats. Four groups of Ss were run to a criterion of 18 correct responses in 20 consecutive trials, one group receiving no reversal, a second group receiving a single reversal trial on trial 1, a third group receiving a reversal trial immediately after reaching a $5 / 6$ criterion, and the fourth group receiving its reversal immediately after reaching a $9 / 10$ criterion. In addition, $8 \mathrm{Ss}$ from the nonreversed group were given a reversal trial after meeting the $18 / 20$ criterion and were then run to the same criterion once again. The effects of cue-reversal proved to be nonmonotonically related to amount of prior learning. No effect occurred until some learning had manifest itself, and the effect was fairly constant over the moderate ranges of learning. Reversal after the $18 / 20$ criterion had no effect.
\end{abstract}

\section{Problem}

Because of its relevance to the continuity-noncontinuity issue, considerable attention has been focused on the effects of cue-reversal on the rate of acquisition of discrimination problems, but, probably because of the almost exclusive interest in theory-testing, there has been practically no attention given to the influence of cue-reversal on Ss under strong aversive control. Neither have attempts been made to measure cuereversal effects over a range of habit strengths which encompasses both the earliest phase of learning and a period at which the discrimination has been firmly established. Yet aversive control procedures are widely used in establishing discrimination habits, and it is well known that they often give rise to patterns of behavior which differ markedly from those generated by positive reinforcement (e.g., Church, 1963). It has even been suggested that discrimination learning motivated by relief from nociceptive stimulation has a different neural locus than positively reinforced learning (Sechzer, 1964).

In the present experiment, an attempt was made to learn more about the effects of cue-reversal on discrimination learning under shock motivation. This was done by measuring the effects on rate of acquisition of introducing a single cue-reversed trial at five different levels of learning.

\section{Subjects}

The Ss were 35 Sprague-Dawley albino rats ranging from 90 to 150 days of age at the beginning of the experiment.

\section{Apparatus}

The discrimination apparatus was similar to that described by Thompson \& Bryant (1955). Built of wood, it was painted grey and consisted of a startbox and runway (either of which could be electrified) and a divided goalbox with two entryways. Another shock-grid extended 4 in from the front of either entryway. Doors for the entryways were constructed of plastic sheeting, one door having been painted white and the other black.

\section{Proeedure}

Habituation and Pretraining. Pretraining was given on two consecutive days. On Day 1 , each $\mathrm{S}$ was given a $1 / 2 \mathrm{hr}$. habituation period in the discrimination apparatus. On Day 2, Ss were avoidance trained by placing them in the startbox and electrifying the grid after $5 \mathrm{sec}$. if $\mathrm{S}$ had not moved out, then, after $S$ had reached the runway, electrifying the grid after $30 \mathrm{sec}$. until $\mathrm{S}$ entered the goalbox. Three consecutive runs from start to goalbox without being shocked constituted the criterion for completion of pretraining. Ss were then trained to knock over the goalbox entryway doors, two grey doors being placed a few inches behind the aperture into which the entryway doors normally fit and brought up to the aperture in several stages. Each $\mathrm{S}$ was run until five consecutive avoidances were made with the doors in place.

Discrimination Training. During discrimination training, the correct cue was always black. The incorrect door was locked and the grid in front of it was always electrified. If $\mathrm{S}$ was shocked by this grid, an error was scored for the trial. The left-right position of the cues was varied across trials in accordance with a Gellerman Series, and Ss were run 25 trials daily. In Group 0, 11 Ss were run until a criterion of 18 correct responses in 20 consecutive trials had been reached, no reversal trial being given to this group. The remaining groups, each containing eight Ss, were all ultimately run to the same $18 / 20$ criterion. Group 1 received a cue-reversal trial on the very first training trial, Group 5/6 encountered a reversal on the trial immediately following achievement of a criterion of five correct responses in six consecutive trials, and Group 9/10 received its reversal trial immediately after reaching a $9 / 10$ criterion. Eight Ss from Group 0 were given a reversal trial after reaching the $18 / 20$ criterion, and were run to the same criterion once again. This last group is termed Group $18 / 20$. 


\section{Results}

The mean number of trials to criterion for Ss in groups $0,1,5 / 6$. and $9 / 10$ were $28.0,21.6,37.6$, and 45.0 , respectively. Although all groups learned rapidly whether they had received a reversal trial or not, animals receiving the trial after some learning had manifest itself generally took longer to reach criterion than those which either encountered no reversal or encountered it on trial one. An analysis of variance revealed that treatment effects were significant $(F=$ 6.07 ; $\mathrm{df}=3,31 ; \mathrm{p}<.01$ ). Group 1 did not differ significantly from Group 0 , nor did the 5/6 and 9/10 groups differ significantly from each other. The main treatment difference appears to have been between groups receiving the reversal trial before learning and those receiving it after some learning had manifest itself. Comparison of pooled data for groups 1 and 2 with similarly pooled scores from groups 3 and 4 showed highly reliable difference $(t=5.27 ; d f=33 ; p<.001)$.

Presentation of a reversal trial after Ss had met an $18 / 20$ criterion had a negligible effect, the median number of trials taken to reach the same criterion a second time being zero, and the mean 0.75 .

\section{Diseussion}

The magnitude of the effect of cue-reversal on rate of acquisition in the present experimental situation appears to vary in a nonmonotonic fashion as a function of degree of learning prior to reversal. Trial one reversal gives rise to no measureable effect, then the effect grows until it apparently reaches a maximum just after Ss reach a criterion of nine correct responses in 10 consecutive trials. At levels of learning somewhat above this, a single reversal trial once again has no detectable effect. The magnitude of the effect generated by a single reversal trial is quite large at the peak level of effectiveness, the $9 / 10$ group taking $60.7 \%$ more trials to reach criterion than the non-reversal controls.

It is interesting to note that the general form of the function relating habit strength to magnitude of cuereversal effects which was obtained under the shock motivation conditions of the present study corresponds quite closely to that which would be predicted by Spence's theory (Spence, 1936) for the positive reinforcement situation. Increments in inhibition are small at low levels of habit strength, and increase monotonically with increases in habit strength, thus accounting for increases in the effectiveness of a reversal trial at moderate levels of learning. At still higher levels, the difference in habit strengths attached to the correct and incorrect stimulus is so great that no detectable effect will result from one reversal trial. It is to be emphasized, however, that the present data seem to be quite consistent with other theories such as the one proposed by Goodwin \& Lawrence (1955) and by Sutherland (1959).

At first blush, it may seem that the nonmonotonic relationship between the effects of reversal and amount of prior learning observed in the present experiment is inconsistent with the findings of such experimenters as Reid (1953) and Pubols (1956) that increasing amounts of overtraining facilitate reversal learning. In these studies, there appears to be no inversion of the facilitative effects of training as very high levels of prior learning are reached. However, it is important to distinguish between the rate of acquisition of the reversal problem and the tendency to persist in responding to the formerly correct cue. As Pubols (1956) observed, facilitative effects of overtraining on rate of reversal acquisition may occur concomitantly with an increased tendency to persist in responding to the correct cue of the prior problem. It is the latter tendency which is being most directly observed in the present experiment.

In general, then, it may be concluded that the findings reported here are in consonance with previous observations made under conditions of positive reinforcement. This suggests that, for the present level of observation at least, a single theoretical scheme may be made to encompass both the positive and the aversive control situations.

\section{References}

CHURCH, R. M. The varied effects of punishment on behavior. Psychol. Rev., 1963, 70, 369-402.

GOODWIN, W. R., \& LAWRENCE, D. H. The functional independence of two discrimination habits associated with a constant stimulus situation. J. comp. physiol. Psychol., 1955, 48, 437-443.

PUBOLS, B. H. Jr. The facilitation of visual and spatial discrimination reversal by overlearning. J. comp. physiol. Psychol., 1956, $49,243-248$.

REID, L. S. The development of noncontinuity behavior through continuity learning. J. exp. Psychol., 1953, 46, 107-112.

SECHZER, J. A. Successful interocular transfer of pattern discrimination in "split-brain" cats with shock-avoidance motivation. J. comp. physiol. Psychol., 1964, 58, 76-83.

SPENCE, K. W. The nature of discrimination learning in animals. Psychol Rev., 1936, 43, 427-49.

SUTHERLAND, N. S. Stimulus analysing mechanisms. In Proceedings of a symposium on the mechanisation of thought processes. Vol. 2. London: Her Majesty's Stationary Office, 1959, 575-609.

THOMPSON, R., \& BRYANT, H. Memory as affected by activity of the relevant receptor. Psychol. Rep., 1955, 1, 393-400.

Notes

1. This investigation was supported in part by fund 8200 of the Neuropsychology Laboratory, USVA Hospital, Kansas City.

2. Present address: Department of Psychology, University of Alberta, Calgary, Alberta, Canada. 